Marquette University

e-Publications@Marquette

$4-2008$

\title{
Thermal Stability and Degradation Kinetics of Polystyrene/ Organically-Modified Montmorillonite Nanocomposites
}

\author{
Grace Chigwada \\ Marquette University \\ Everson Kandare \\ Marquette University \\ Dongyan Wang \\ Cornell University \\ Stephen Majoni \\ Marquette University \\ Darlington Mlambo \\ Marquette University
}

See next page for additional authors

Follow this and additional works at: https://epublications.marquette.edu/chem_fac

Part of the Chemistry Commons

\section{Recommended Citation}

Chigwada, Grace; Kandare, Everson; Wang, Dongyan; Majoni, Stephen; Mlambo, Darlington; Wilkie, Charles A.; and Hossenlopp, Jeanne M., "Thermal Stability and Degradation Kinetics of Polystyrene/OrganicallyModified Montmorillonite Nanocomposites" (2008). Chemistry Faculty Research and Publications. 363.

https://epublications.marquette.edu/chem_fac/363 


\section{Authors}

Grace Chigwada, Everson Kandare, Dongyan Wang, Stephen Majoni, Darlington Mlambo, Charles A. Wilkie, and Jeanne M. Hossenlopp

This article is available at e-Publications@Marquette: https://epublications.marquette.edu/chem_fac/363 


\title{
Thermal Stability and Degradation Kinetics of Polystyrene/Organically-Modified Montmorillonite Nanocomposites
}

\author{
Grace Chigwada ${ }^{1}$, Everson Kandare ${ }^{1}$, Dongyan Wang ${ }^{2}$, Stephen Majoni ${ }^{1}$, \\ Darlington Mlambo ${ }^{1}$, Charles A. Wilkie ${ }^{1}$, and Jeanne M. Hossenlopp ${ }^{1, *}$ \\ ${ }^{1}$ Department of Chemistry, Marquette University, Milwaukee, WI 53201-1881, USA \\ ${ }^{2}$ Department of Materials Science and Engineering, Cornell University, Ithaca, NY 14853-1501, USA
}

\begin{abstract}
Organically-modified montmorillonite (MMT) clays have been prepared using ammonium salts containing quinoline, pyridine, benzene, and styrenic groups. The nanocomposites were prepared by melt blending and the formation of nanocomposites was characterized using X-ray diffraction (XRD) and transmission electron microscopy (TEM). Thermal stability and flammability were evaluated by thermogravimetric analysis (TGA) and cone calorimetry measurements, respectively. The presence of modified MMT at $5 \%$ loading resulted in significant improvement in thermal stability compared to the virgin polymer. Effective activation energies for mass loss were determined via a model-free isoconversional approach from TGA data obtained under $\mathrm{N}_{2}$ and under air. The additives served to raise the activation energy, with a more significant impact observed under pyrolysis conditions. The onset temperature of degradation and temperature of maximum decomposition rate are increased, while the peak heat release rate and mass loss rates are significantly reduced in the presence of three of the modified clays. No reduction in the total heat released is observed.
\end{abstract}

Keywords: Polystyrene Nanocomposites, Thermal Stability, Montmorillonite, Degradation Kinetics, Activation Energies.

\section{INTRODUCTION}

Polystyrene (PS) has an enormously versatile array of properties and a wide range of applications. In order to improve the physical properties of PS such as thermal stability, flame retardancy, tensile strength, flexural modulus, reduced gas and moisture permeability, and solvent resistancy, many researchers have turned their attention to the formation of polystyrene/modified-montmorillonite (MMT) clay nanocomposites. ${ }^{1-14}$ In nanocomposite formation, modified-MMT clays with nanometer sized galleries are dispersed into the polymer matrix and the resultant interfacial interactions between the silicate layers and the polymer matrix are key to the observed enhancement in the physical properties. MMT based layered silicates have been extensively used by virtue of being ubiquitous and their ease of processing.

Pristine MMT contains alkali and/or alkali earth metal ions sandwiched between negatively charged layers to balance the charge deficiency created by isomorphous substitution within the layers of tetrahedral $\mathrm{Si}^{4+}$ by $\mathrm{Al}^{3+}$

\footnotetext{
${ }^{*}$ Author to whom correspondence should be addressed.
}

or octahedral $\mathrm{Al}^{3+}$ by $\mathrm{Mg}^{2+}$ respectively. Because of the relatively-high cationic exchange capacity (CEC) exhibited by MMT, it is easy to exchange the interlayer cations with ammonium or phosphonium cations. ${ }^{2-4,6-12,15,16}$ The intercalation of long chain ammonium salts results in increased interlayer spacing and/or exfoliation, promoting easy penetration of monomer or polymer chains. The presence of organic modifiers is vital for good nanocomposite formation, improving compatibility between the additive and the respective polymer. ${ }^{8}$ Various methods have been employed to prepare MMT based nanocomposites such as melt intercalation, ${ }^{3,12,17-19}$ emulsion polymerization, ${ }^{4}$ solution blending, ${ }^{7}$ suspension polymerization, ${ }^{8}$ and in situ free radical bulk polymerization. ${ }^{11,16}$

Any method involving polymerization in the presence of the additive opens the possibility of generating different molecular weight distributions than would be found in reference samples synthesized without additives. Wall and coworkers ${ }^{20}$ and Carasco and Pages ${ }^{21}$ have shown that polymer properties, especially thermal degradation, are dependent on the polymer molecular weights. In this paper, polystyrene/modified-MMT nanocomposites have 
been prepared using melt intercalation to avoid the problem of possibly dissimilar molecular weights. The objectives are to

(i) confirm the enhancement in thermal stability following nanocomposite formation,

(ii) compare thermal stability of various nanocomposites as evaluated by thermogravimetric analysis, (TGA), and

(iii) compare their flammability properties using cone calorimetry measurements.

From TGA mass loss derived degradation kinetics of polystyrene nanocomposites, a correlation between observed apparent activation energies and thermal stability, defined here, as the shift of degradation temperatures to higher values, is examined.

\section{EXPERIMENTAL DETAILS}

\subsection{Materials}

Polystyrene $\left(M_{\mathrm{w}}\right.$ ca. $230000, M_{\mathrm{n}}$ ca. 140000 melt index $6.0-9.0 \mathrm{~g} / 10 \mathrm{~min}$ at $200{ }^{\circ} \mathrm{C} / 5 \mathrm{Kg}$ ), benzoyl peroxide (BPO) initiator, diethyl ether, tetrahydrofuran (THF), hexadecyl bromide, acetone, quinoline, and pyridine were obtained from Aldrich Chemical Co. Montmorillonite (MMT) and Cloisite 10A were kindly provided by Southern Clay Products, Inc. Cloisite 10A is an organically-modified montmorillonite, containing dimethyl, benzyl, and hydrogenated tallow quaternary ammonium cation. Hydrogenated tallow is a mixture of $\sim 65 \% \mathrm{C} 18, \sim 30 \% \mathrm{C} 16$, and $\sim 5 \% \mathrm{C} 14$ chains. All chemicals were used without further purification with the exception of styrene monomer solution where the tert-butylcatechol was removed by passing through an inhibitor-removal column (Aldrich).

\subsection{Preparation of Ammonium Salts}

$N, N$-dimethyl- $n$-hexadecyl-(4-vinylbenzyl) ammonium chloride (VB16), ${ }^{1}$ quinolinium hexadecyl ammonium bromide (QC16), ${ }^{22}$ and pyridium hexadecyl ammonium bromide (PYC16) ${ }^{22}$ were prepared following previously reported methods. A second batch of QC16 was synthesized using a slightly modified route from that reported in Ref. [22]. $10.0 \mathrm{~g}(77.4 \mathrm{mmol})$ of quinoline was dissolved in $150 \mathrm{ml}$ of acetone and stirred for a few minutes. To the resultant solution, $23.6 \mathrm{~g}(77.4 \mathrm{mmol})$ of hexadecylbromide $(\mathrm{C} 16 \mathrm{Br})$ was gradually added and the mixture was refluxed for $48 \mathrm{hrs}$. Most of the solvent was removed under vacuum and $20.0 \mathrm{ml}$ of acetone was added to the remaining solution. The mixture was refluxed for another 24 hours and most of the solvent removed under vacuum. The remaining solution was cooled in an ice water bath and the resulting precipitate was washed with ether. The final yield was $15 \%$. The ${ }^{1} \mathrm{H}$ NMR for the product in $\mathrm{CDCl}_{3}$ was as follows: $\delta 10.42-10.44(\mathrm{~m}, 1 \mathrm{H}) ; \delta 9.15$ $(d, J=8.411 \mathrm{H}) ; \delta 8.36(d, J=9.62 \mathrm{H}) ; \delta 8.13-8.21$ $(\mathrm{m}, 2 \mathrm{H}) ; \delta 7.89-7.95(\mathrm{~m}, 1 \mathrm{H}) ; \delta 5.36(t, J=7.5,2 \mathrm{H})$; $\delta 1.99-2.09(\mathrm{~m}, 2 \mathrm{H}) ; \delta 1.124-1.25(\mathrm{~m}, 26 \mathrm{H}) ; \delta 0.81(t$, $6.72,3 \mathrm{H})$.

\subsection{Modification of the Smectite Clays}

Ammonium cations were exchanged for the $\mathrm{Na}^{+}$ions in MMT by dissolving these respective salts in $100 \mathrm{~mL}$ of THF and then mixing with a calculated amount of clay dispersed in $200 \mathrm{~mL}$ of a 2:1 water/THF solution. The amounts of the exchange salts were determined so as to have $20 \%$ excess based on the cationic exchange capacity (CEC) of the clay. The mixture was stirred at room temperature for $24 \mathrm{~h}$ and the resultant precipitate was continuously washed with water until no halide ions were detected. The modified MMT was dried in a vacuum oven for 24 hours.

\subsection{Preparation of the Polystyrene/Clay Nanocomposites}

Polystyrene/clay nanocomposites were prepared via melt blending using established methods. ${ }^{23}$ Polystyrene nanocomposites were prepared from respective additives by mixing $5 \mathrm{~g}$ of the additive with $95 \mathrm{~g}$ of pristine polystyrene to achieve 5\% mass fractions. Melt blending was then performed on a Brabender mixer for 15 minutes at a temperature of about $190{ }^{\circ} \mathrm{C}$ and speed of $60 \mathrm{rpm}$. The prepared composites are identified as PS-QC16, PS-PYC16, PS-VB16, and PS-10A for QC16, PYC16, VB16, and 10A additives respectively. A reference sample of pure polystyrene was obtained following the same procedure in the absence of any additive.

\subsection{Analysis}

X-ray diffraction (XRD) patterns of the synthesized layered materials were obtained from a 2 circle Rigaku powder diffractometer operating in the parafocusing Bragg-Bretano configuration, with a $(1 / 2)^{\circ}$ divergence slit, $(1 / 2)^{\circ}$ scatter slit, $0.15 \mathrm{~mm}$ receiving slit, $0.15 \mathrm{~mm}$ monochromator receiving slit using $\operatorname{CuK} \alpha(\lambda=1.54 \AA)$ radiation source operated at $50 \mathrm{kV}$ and $20 \mathrm{~mA}$, with data acquisition done in $2 \theta$ steps of 0.036 per $20 \mathrm{~s}$. Powdered samples were cold-pressed into $1 \mathrm{~mm}$ platelets, which were then mounted onto vertically oriented sample holders for XRD analysis. Basal spacing of the synthesized clays and polymer composites were obtained from the 001 reflection after fitting the data to a pseudo-Voight function with $\mathrm{XFIT}^{24}$ stripping off the $\mathrm{CuK} \alpha_{2}$ contributions. Bright field transmission electron microscopy (TEM) images of the nanocomposites were obtained at $60 \mathrm{kV}$ with a Zeiss 10c electron microscope. The samples were ultramicrotomed with a diamond knife on a Richert-Jung Ultra-Cut E microtome at room temperature to give $\sim 700 \AA$ thick section. The sections were then transferred from the knifeedge to 300 hexagonal mesh $\mathrm{Cu}$ grids. 
Thermogravimetric analysis, (TGA) and differential thermal analysis (DTA) were performed on a SDT 2960 simultaneous DTA-TGA instrument using $21.0 \pm 1.0 \mathrm{mg}$ samples contained in aluminum cups. TGA experiments were performed over a temperature range of $50-600{ }^{\circ} \mathrm{C}$ using constant heating rates of $5,10,15,20$, and $25^{\circ} \mathrm{C} / \mathrm{min}$ in $\mathrm{N}_{2}$ or in air flowing at $85 \pm 5 \mathrm{~mL} / \mathrm{min}$.

Cone calorimetry was performed on an Atlas Cone 2 instrument using an incident flux of $35 \mathrm{~kW} / \mathrm{m}^{2}$ with a cone shaped heater; the spark was continuous until the sample ignited. Approximately $30 \mathrm{~g}$ of polystyrene composite samples were compression molded into $10 \mathrm{~cm} \times$ $10 \mathrm{~cm}$ square plaques of uniform thickness $(\sim 3 \mathrm{~mm})$ for cone analysis. All samples were run in triplicate and the average value, with standard deviation, is reported; results from cone calorimeter are generally considered to be reproducible to $\pm 10 \% .{ }^{25}$

\section{RESULTS AND DISCUSSION}

Pyridium hexadecyl ammonium bromide (PYC16), quinolinium hexadecyl ammonium bromide (QC16), and $N, N$ dimethyl- $n$-hexadecyl-(4-vinylbenzyl) ammonium chloride (VB16) were used to modify the $\mathrm{Na}^{+}$intercalated MMT and their chemical structures are shown in Figure 1. These surfactants were chosen to demonstrate particular points of interest in nanocomposite formation. Each salt contains a long organic chain (typically $\mathrm{C} 16$ ) which is chemically attached to different moieties such as pyridinium, quinolinium, styrenic group, and a phenyl ring. This enables us to investigate the effect of the end groups on the thermal stabilization of PS nanocomposites.

The layered structure of modified-MMT clays, QC16 and PYC16 and their corresponding polystyrene nanocomposites were examined by XRD and have been reported elsewhere. ${ }^{22}$ Exchanging $\mathrm{Na}^{+}$ions with organic cations resulted in significant increments in the basal spacing. The

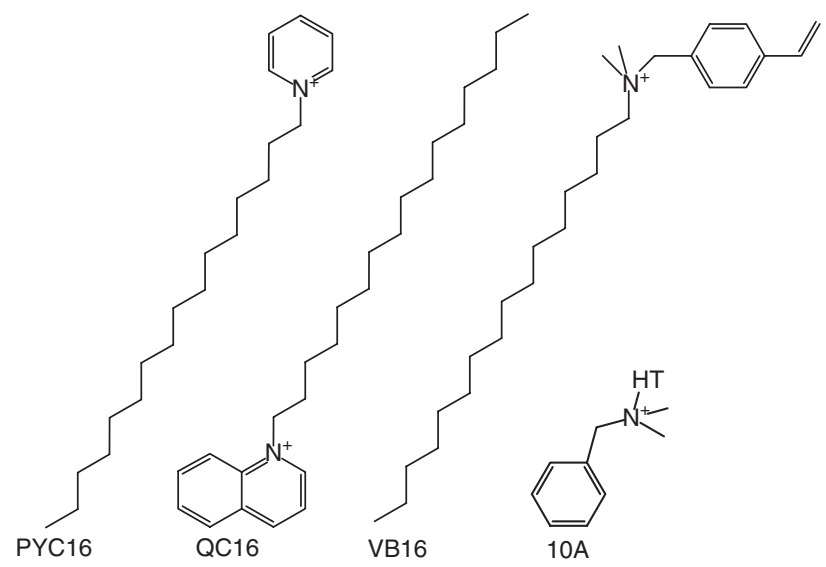

Fig. 1. Structures of the salts used to prepare the organically modified clays. HT represents hydrogenated tallow, a mixture of $\sim 65 \% \mathrm{C} 18$, $\sim 30 \% \mathrm{C} 16$, and $\sim 5 \% \mathrm{C} 14$ chains.

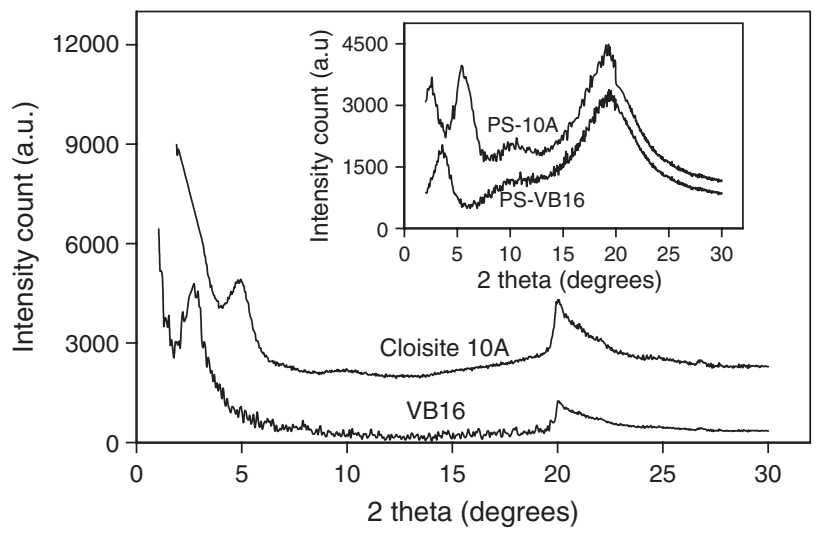

Fig. 2. XRD data for Cloisite $10 \mathrm{~A}$ and VB16 clays. Insert shows XRD data for Cloisite 10A and VB16 polystyrene/clay nanocomposites. Data are offset for clarity but otherwise not scaled.

characteristic 001 peak for $\mathrm{Na}^{+}$containing MMT is at $2 \theta=7.9$, corresponding to basal spacing, $d$, of $11.2 \AA$ while the 001 peaks for the modified clays are shifted to lower $2 \theta$ values (e.g., larger $d$ values) confirming a successful intercalation of the longer cations. The XRD patterns for $10 \mathrm{~A}$ and VB16 clays and their respective PS nanocomposites are shown in Figure 2. Basal spacing increments of 6.7 and $21.0 \AA$ were observed for $10 \mathrm{~A}$ and VB16, respectively, following exchange of $\mathrm{Na}^{+}$ions. Upon melt blending, 001 reflections were further shifted to lower $2 \theta$ values for PS-QC16, 22 PS-PYC16, ${ }^{22}$ and PS-10A consistent with formation of intercalated nanocomposites. The calculated basal spacings are 34.0, 29.0, ${ }^{22} 33.0,{ }^{22}$ and $24.3 \AA$ for PS-10A, PS-QC16, PS-PYC16, and PS-VB16 polystyrene/clay nanocomposites respectively. The intercalated polymer chains are known to adopt a flattened configuration between the silicate layers, since the melt radius of gyration of PS chains $(\sim 95.9 \AA)^{19,26}$ is larger than the observed increments in $d$ upon melt intercalation in all cases. Note that a reduction in the basal spacing is observed for PS-VB16 compared to that in the original VB16 additive. This is not uncommon as Jang and coworkers $^{27}$ made a similar observation for polystyrene nanocomposites made via melt intercalation. The 001 peaks in the polymer/clay samples are broad, suggesting possible layer disorder and/or exfoliation, however XRD cannot be used alone to evaluate these possibilities.

Transmission electron microscopy (TEM) can be used to more directly evaluate whether some exfoliated phases exist within the polymer matrix. The low magnification images provide information about the nano-dispersion while high magnification images tell whether exfoliation and/or intercalation have been achieved. Chigwada and coworkers $^{22}$ reported the TEM image of PSQC-16 at low resolution to appear as regions of alternating narrow, dark bands, and wide light bands. The dark lines correspond to clustered clay particles (tactoids and agglomerates). The absence of parallel and equally spaced lines at higher 
resolution suggests no intercalation of PS into QC16 layers but this is not consistent with the XRD results. They also observed that the dispersion of clay layers is improved for the PS-PYC16 as can be seen in the low magnification image. The higher magnification image permits the observation of discrete clay layers suggesting co-existence of exfoliation and intercalation.

At low magnification (not shown) TEM images for PS-10A and VB16 in polystyrene indicate good dispersion without the presence of large tactoids. The TEM image of PS-10A at high magnification is shown in Figure 3(A). The $10 \mathrm{~A}$ layers in parallel registry (dark regions) reveal periodical stacking consistent with intercalation as evident from XRD results. High resolution TEM image of PS-VB16 is shown in Figure 3(B). The overall picture shows that the modified MMT layers did not occupy the full volume with regions of pure PS visible. The TEM image suggests the existence of both intercalated and exfoliated regions.

(A)

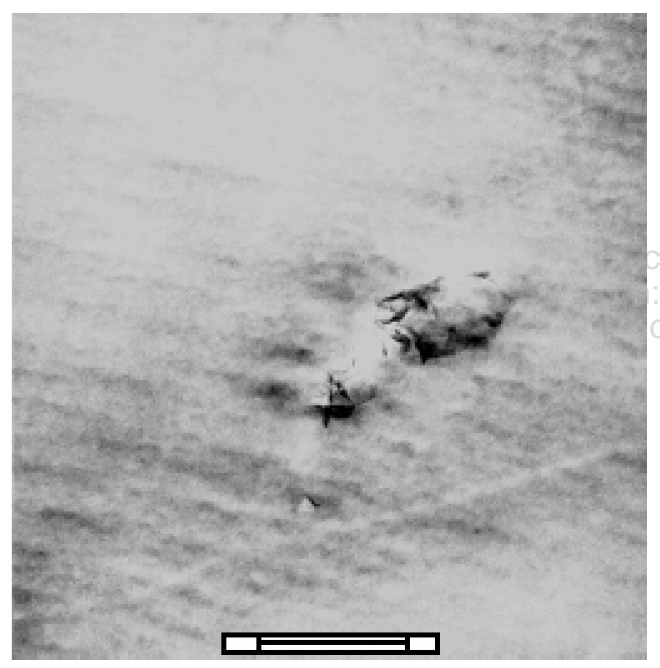

(B)

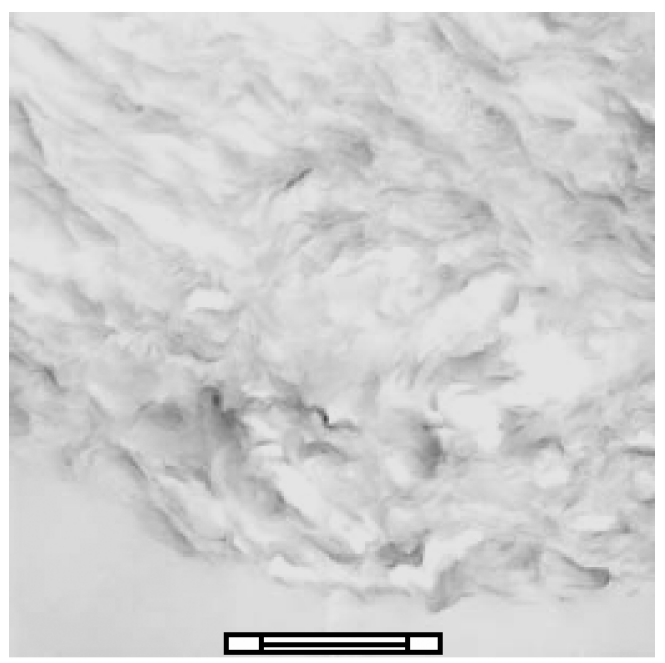

Fig. 3. (A) TEM image at high magnification for PS-10A. The scale bar (bottom centre) represents $100 \mathrm{~nm}$. (B) TEM image at high magnification for PS-VB16. The scale bar (bottom centre) represents $100 \mathrm{~nm}$.
Other work on PS-VB16 nanocomposites indicate that the type of nanocomposites formed depends on the preparation methodology. Zhu and coworkers assigned the nanocomposite formed via bulk polymerization to be totally exfoliated. ${ }^{1}$ There has been some discussion in the literature concerning the possibility of forming exfoliated polymer-clay nanocomposites using clays with single chain organic modifiers such as those used here. Initial work by Gilman and coworkers ${ }^{25}$ suggested that exfoliation would not occur with bulk polymerized polymers with single-chain modified clays. However, Gilman and Morgan $^{28}$ were later able to demonstrate formation of an exfoliated PS nanocomposite using VB16, a single chain organic modifier. We note here that different preparative methods lead to differences in additive dispersion and the distribution of nanocomposites (intercalated and/or exfoliated) within the polymer matrix. However, in all cases examined here, the presence of a fairly good homogeneous distribution of respective additives shows that the melt blending method generally has favorable thermodynamics of mixing.

Thermogravimetric analysis (TGA) data for pure polystyrene and its nanocomposites heated under $\mathrm{N}_{2}$ are shown in Figure 4(A) while their corresponding derivatives (DTG) are shown in Figure 4(B). The onset of thermal

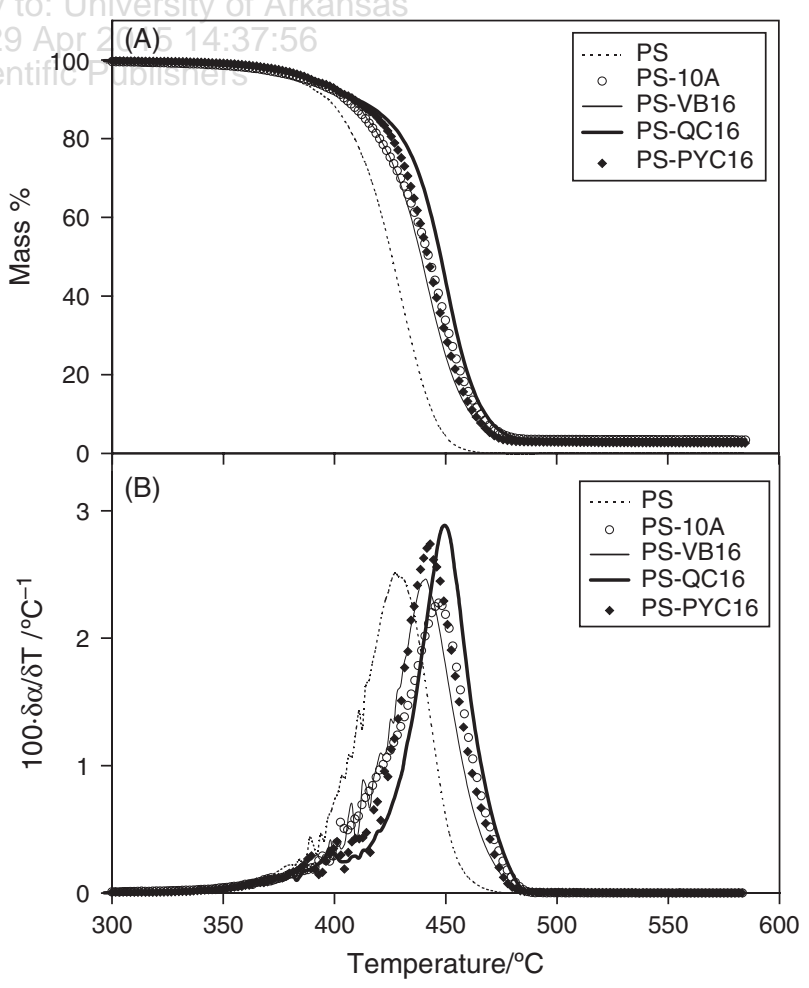

Fig. 4. (A) TGA curves for pure PS (dashed line), PS-VB16 (solid line), PS-PYC16 (solid diamonds), PS-10A (empty circles), and PS-QC16 (bold line). (B) DTG curves for pure PS (dashed line), PS-VB16 (solid line), PS-PYC16 (solid diamonds), PS-10A (empty circles), and PS-QC16 (bold line). Derivatized mass losses are scaled by a factor of 100 . 
Table I. TGA data for polystyrene nanocomposites.

\begin{tabular}{lccccc}
\hline Sample & $T_{10}$ & $T_{50}$ & $\Delta T_{50}$ & $T_{\mathrm{m}}$ & Char (\%) \\
\hline PS & $397 \pm 0$ & $426 \pm 0$ & 0 & $431 \pm 1$ & $1 \pm 0(0)$ \\
PS/10A & $405 \pm 1$ & $442 \pm 0$ & $16 \pm 0$ & $445 \pm 1$ & $3 \pm 1(3)$ \\
PS/QC16 & $409 \pm 1$ & $448 \pm 1$ & $22 \pm 1$ & $450 \pm 0$ & $4 \pm 1(4)$ \\
PS/VB16 & $407 \pm 1$ & $439 \pm 0$ & $13 \pm 0$ & $440 \pm 1$ & $4 \pm 0(3)$ \\
PS/PYC16 & $409 \pm 1$ & $442 \pm 0$ & $16 \pm 0$ & $443 \pm 0$ & $3 \pm 1(4)$ \\
\hline
\end{tabular}

$T_{10}$, temperature at which $10 \%$ mass loss occurs; $T_{50}$, temperature at which $50 \%$ mass loss occurs; $\Delta T_{50}, T_{50}$ (composite) minus $T_{50}$ (pure PS); $T_{\mathrm{m}}$, temperature at maximum degradation rate. Italicized entries are the expected char based on the residue obtained from pure PS and additive fractions.

degradation, measured as the temperature at which $10 \%$ mass loss occurs, $T_{10}$, is shifted to higher temperatures for all nanocomposites relative to pure PS. This behavior is maintained throughout the thermal decomposition. $T_{50}$, the temperature at which $50 \%$ mass loss occurs, and $T_{\max }$, temperature at maximum degradation rate, also shift to higher values for the nanocomposites; in some cases $\Delta T_{50}$ ( $T_{50}$ for PS nanocomposites minus $T_{50}$ for PS) is as high as $22{ }^{\circ} \mathrm{C}$. Given the small amount of the clay phase, this improvement in thermal stability is significant. From DTG curves, Figure 4(B), significant mass losses are seen from about $375^{\circ} \mathrm{C}$. TGA data are summarized in Table I. Other authors have reported similar observations for polystyrene nanocomposites prepared by melt blending using modified MMT clays. ${ }^{10,29} T_{50}$ values are consistently lower, by $\sim 12{ }^{\circ} \mathrm{C}$, than found in earlier work ${ }^{22}$ for melt-blended PS, PS-QC16, and PS-PYC16, however $\Delta T_{50}$ values are similar, within experimental uncertainty. Use of a different instrument here may be the source of differences.

Mass difference curves (mass \% of PS nanocomposites minus mass $\%$ of pure PS at the same temperature) for polystyrene nanocomposites are shown in Figure 5(A). The $\Delta$ mass percentages are positive over the entire degradation temperature range for all investigated nanocomposites. This shows that the polystyrene nanocomposites are more thermally stable than the virgin polymer under the thermo-degradation processes involved. Maximum stabilization was observed at the temperature at which the highest mass loss rate occurs, an indication that addition of various MMT based additives prevents or retards depolymerization occurring via random chain scission. A simple comparison of the observed shifts in thermal degradation temperatures suggests the following order regarding thermal stability for the nanocomposites under investigation: PS-QC16 $\gg$ PS-PYC16 PS-10A > PS-VB16. The presence of a quinoline group in QC16 may render it more effective in thermal stabilization when compared to other phenyl groups containing additives.

Differential thermal analysis (DTA) curves of pure PS and its nanocomposites are shown in Figure 5(B). The DTA curve for pure PS is similar to that of its respective nanocomposites with the exception that the endothermic feature at around $440{ }^{\circ} \mathrm{C}$ is shifted to relatively higher temperatures and is less pronounced for the

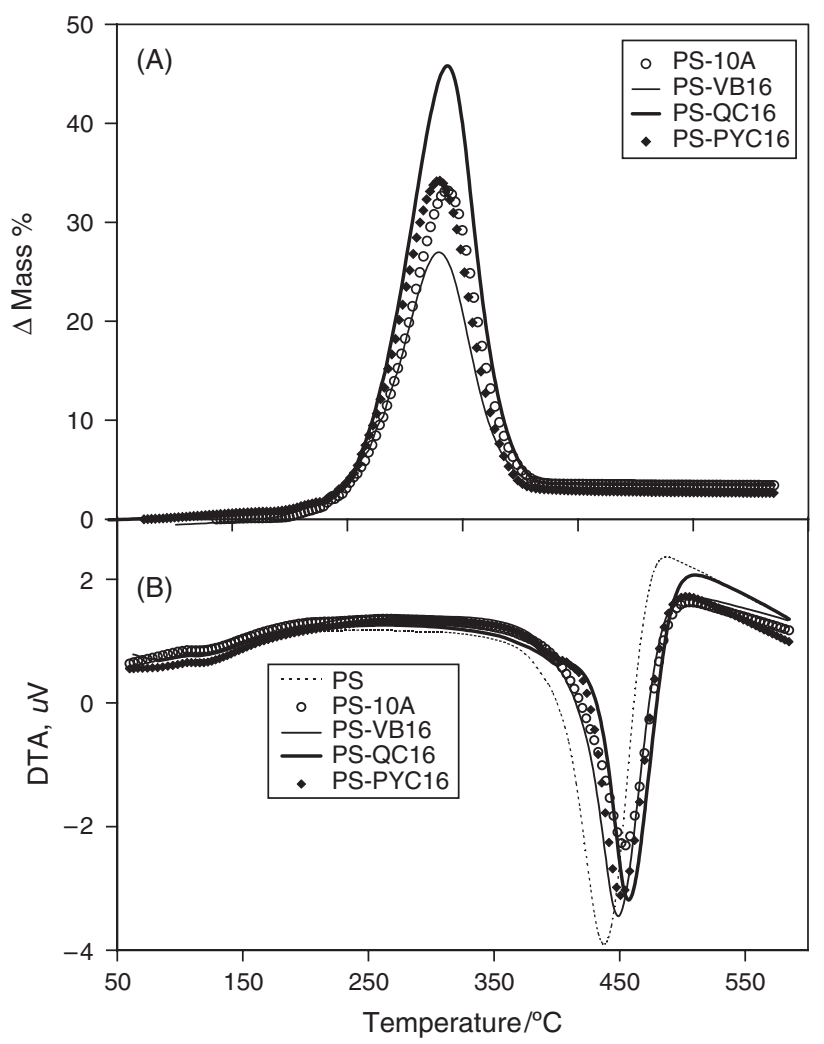

Fig. 5. (A) Curves of mass loss differences for PS nanocomposites; pure PS (dashed line), PS-VB16 (solid line), PS-PYC16 (solid diamonds), PS-10A (empty circles), and PS-QC16 (bold line) as a function of degradation temperature. (B) DTA curves for pure PS (dashed line), PS-VB16 (solid line), PS-PYC16 (solid diamonds), PS-10A (empty circles), and PS-QC16 (bold line).

nanocomposites. This is additional evidence of enhanced thermal stability for the nanocomposites manifested in the positive degradation temperature shifts. Since the DTA profiles of nanocomposites have the same features as pure PS, it is proposed here that there is no significant change in the degradation mechanism, however, the degradation processes are delayed. To elucidate mechanistic changes if and/or when they occur, evolved products were both qualitatively and quantitatively monitored using gas chromatography-mass spectroscopy (GC-MS) and thermal gravimetric analysis-Fourier transform infrared (TGA-FTIR) for a PS-10A loaded at various percentages. ${ }^{30}$ It was proposed that the degradation pathway of polymers was modified by the presence of the clay. Similarly, identification of evolved gas products and the inorganic residues from the systems being investigated here are necessary to detect mechanistic changes if they occur. This will be the subject of future studies.

Thermal degradation of pure polystyrene has been shown to occur in a single step with styrene monomer and oligomers as the primary volatile products, together with smaller amounts of benzene and toluene (combustibles). ${ }^{31}$ TGA experiments provide a means to extract estimates of kinetic parameters such as activation energies, frequency 
factor, rate of decomposition, and, in some cases, the order of the decomposition reaction. Both isothermal and nonisothermal methods can be used to estimate the abovementioned parameters. In this study a non-isothermal method was used rather than a conversional isothermal one for the following reasons;

(i) it is possible to retrieve characteristic information for a given sample over the entire degradation temperature range,

(ii) samples might undergo some side reactions during the process of raising the temperature to the desired isothermal value, and

(iii) kinetics are established in a continuous fashion over the entire decomposition profile. Dynamic thermogravimetric analysis (linear temperature increase) was employed in this study using multiple heating rates kinetics to estimate apparent activation energies.

There are several mathematical models that could be used to obtain kinetic parameters from these solidstate kinetic data and these are conveniently divided into two groups namely model-fitting and isoconversional (model-free) methods. Model fitting methods have been extensively criticized for non-isothermal applications as regression methods used with these methods sometimes lead to indistinguishable fits between different models. ${ }^{32-35}$ Another major disadvantage inherent in model-fitting methods is that they yield a single average value for the entire degradation process, while the thermal degradation of polymeric materials normally involve multiple steps characterized by different activation energies. ${ }^{35}$ Isoconversional methods have gained wide spread use as they do not have modelistic assumptions, ${ }^{35-38}$ however, their use is governed by assumptions that they are independent of the dynamic heating rate or temperature. ${ }^{37}$ It is therefore possible to calculate the apparent activation energy, $E_{\alpha}$, as a function of the degree of conversion, $\alpha$.

The multiple heating rate kinetics (MHRK) method is used in this study to extract effective kinetic parameters, applying the Flynn-Wall-Ozawa ${ }^{39}$ method specifically derived for heterogeneous chemical reactions under linear heating rates. ${ }^{40-42}$ The derivation of the Flynn-Wall-Ozawa method from first principles is presented in Ref. [39]. Simplified, the Flynn-Wall-Ozawa method is expressed by the equation:

$\log f(x)=\log \left(A E_{\alpha} / R\right)-\log (\beta)-2.315-0.4567 E_{\alpha} / R T$

where $f(x)$ is known as the conversional functional relationship; $A$ is the pre-exponential factor $\left(\mathrm{min}^{-1}\right), E_{\alpha}$ is the apparent activation energy $\left(\mathrm{kJ} \mathrm{mol}^{-1}\right), R$ is the gas constant, $\beta$ is the heating rate $(\mathrm{K} / \mathrm{min})$, and $T$ is the absolute temperature $(\mathrm{K})$. Assuming that the reaction rate is only a function of temperature, Eq. (1) can be further simplified to the model-free expression shown in Eq. (2).

$$
\log (\beta)=-0.4567 E_{\alpha} / R T+\text { constant }
$$

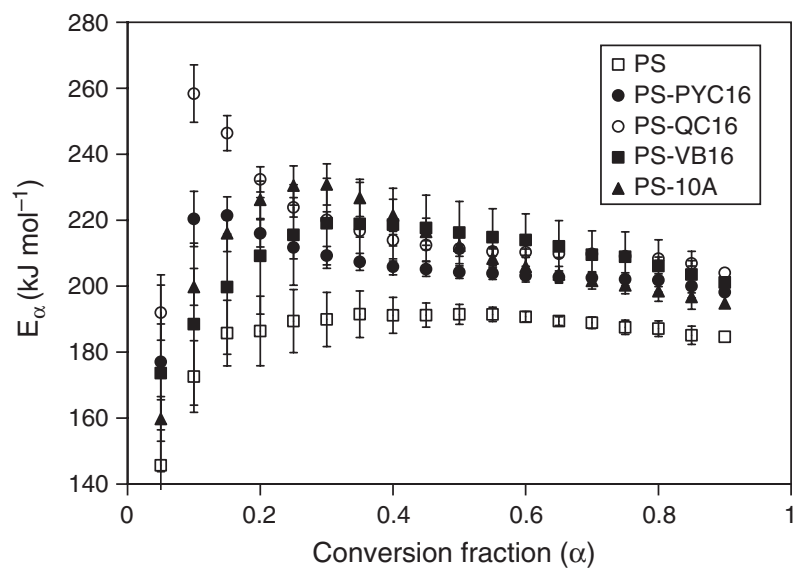

Fig. 6. Plot of $E_{\alpha}$ versus extent of decomposition, $\alpha$, for the nonisothermal degradation of pure PS (empty circles), PS-VB16 (solid triangles), PS-QC16 (empty diamonds), PS-PYC16 (solid circles), and PS-10A (empty squares), under nitrogen. Error bars determined by propagation of uncertainties obtained in fitting data to Eq. (2).

Activation energies were calculated from the slopes of the isoconversional plots of $\log (\beta)$ versus $1 / T$ for fractional conversions $\alpha=0.05-0.90$ at intervals of 0.05 . The obtained effective activation energies are plotted as function of $\alpha$ in Figures 6 through 8 .

From Figure 6, the initial activation energy at $10 \%$ conversion signaling the onset of the decomposition process for pure polystyrene was $170 \mathrm{~kJ} \mathrm{~mol}^{-1}$. At about $30 \%$ conversion, the $E_{\alpha}$ values has risen to $\sim 190 \mathrm{~kJ} \mathrm{~mol}^{-1}$ and this activation value is somewhat maintained throughout the degradation profile. Vyazovkin and coworkers ${ }^{36}$ observed $E_{\alpha}$ values, using commercial polystyrene of molecular weight 124,000 and polydispersity index of 2.7 , in the range of $100-200 \mathrm{~kJ} / \mathrm{mol}$ for a pure PS sample heated under nitrogen. Note that Vyazovkin ${ }^{36-38}$ uses a different method for analysis of non-isothermal data than the FWO model employed here. Effective activation energies are determined by minimizing Eq. (3) over a narrow range of around $\alpha$ using a step size of $\Delta \alpha$.

$$
\begin{aligned}
\Phi\left(E_{\alpha}\right) & =\sum_{i=1}^{n} \sum_{j \neq i}^{n} \frac{J\left[E_{\alpha}, T_{i}\left(t_{\alpha}\right)\right]}{J\left[E_{\alpha}, T_{j}\left(t_{\alpha}\right)\right]} \text { where } J\left[E_{\alpha}, T_{i}\left(t_{\alpha}\right)\right] \\
& \equiv \int_{t_{\alpha-\Delta \alpha}}^{t_{\alpha}} \exp \left[\frac{-E_{\alpha}}{R T_{i}}\right] d t
\end{aligned}
$$

Preliminary results for our data, analyzed by minizing Eq. (3) in Mathcad $^{\odot} 2001$ i, indicate that the general trends observed with the Flynn-Wall-Ozawa are also found via the advanced isothermal method. Figure 7 shows data for PS and PS-VB16, comparing the Flynn-Wall-Ozawa (FWO) analysis with Vyazovkin's method (VYA). As expected, ${ }^{36-38}$ the PS-VB16 activation energies show more significant differences when determined via the two models, since $E_{\alpha}$ depends more strongly upon $\alpha$. Additional work is necessary to evaluate uncertainties in fitting these data to the advanced isoconversional method. 


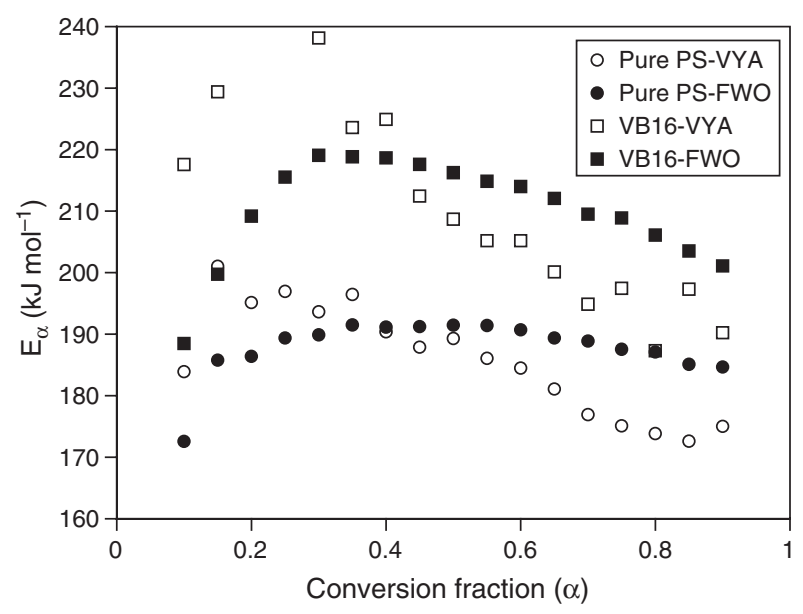

Fig. 7. Comparison of Flynn-Wall-Ozawa (FWO) and Vyazovkin's advanced isoconversional method (VYA) for PS and PS-VB16 decomposition under nitrogen.

The FWO activation energy at $\alpha=0.10$ for PS-QC16 is the highest $\left(260 \mathrm{~kJ} \mathrm{~mol}^{-1}\right)$ followed by that of PS-PYC16 $\left(220 \mathrm{~kJ} \mathrm{~mol}^{-1}\right)$, consistent with the observed slight delay in the onset of thermal degradation, ( $T_{10}$ values, Table I) for these nanocomposites relative to pure PS, PS-10A, and PS-VB16. The $E_{\alpha}$ values for all of the nanocomposites in the $\alpha$ range of $0.20-0.90$ are similar (within experimental uncertainty). Overall, the $E_{\alpha}$ values for the nanocomposites are higher than for pure PS in the conversion fraction region of $0.40-0.90$ by $\sim 20 \mathrm{~kJ} \mathrm{~mol}^{-1}$. This is consistent with the observed enhanced thermal stability for the nanocomposites marked by the shift to higher temperatures of their TGA curves relative to pure PS. The fact that the $E_{\alpha}$ values for the polystyrene nanocomposites are similar within experimental error in the $\alpha$ range of 0.2-0.9 suggests that there is no significant shift in the degradation mechanism between the different clays at higher conversion fractions.

Figure 8 shows a comparison of effective activation energies obtained for heating under $\mathrm{N}_{2}$ versus heating under air for selected nanocomposites and PS. New samples were prepared for this analysis, including synthesis of QC16 (see experimental section for details). PS-QC16 was chosen to verify the high $E_{\alpha}$ for initial mass loss (i.e., at $\alpha=0.1$ ) and PS-10A provides a comparison with behavior observed with the other nancomposites. The data obtained in nitrogen agree with those presented in Figure 6 to within $\pm 10 \%$, indicating good reproducibility in the extraction of effective activation energy.

The corresponding values for $E_{\alpha}$ obtained in air are significantly smaller than those obtained in nitrogen. The PS-QC16 and PS-10A samples have slightly higher $E_{\alpha}$ values than PS alone for conversion fractions in the range of $0.25-0.80$ but the difference is much less pronounced in the case of thermo-oxidative conditions compared to the pyrolysis under nitrogen. This is consistent with the

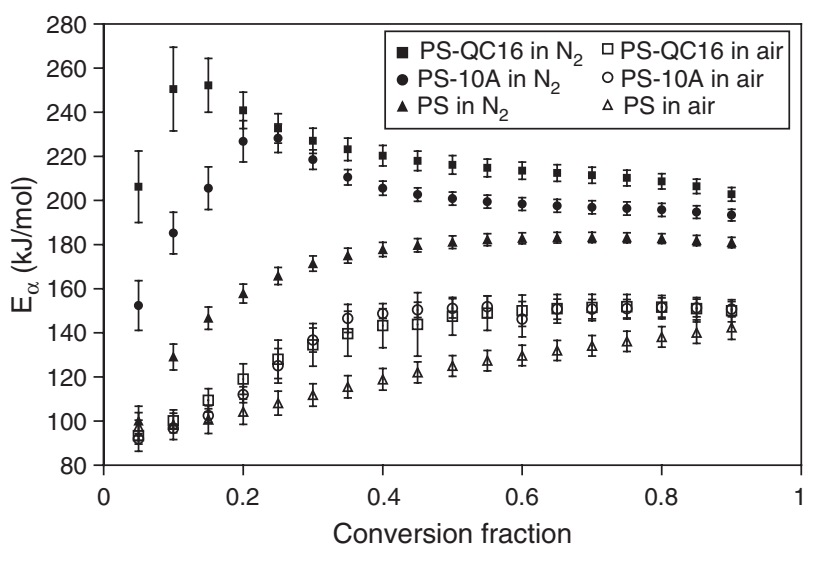

Fig. 8. Plot of $E_{\alpha}$ versus extent of decomposition, $\alpha$, for the nonisothermal degradation of pure PS (triangles) and PS-QC16 (squares) and PS-10A (circles) nanocomposites. Open symbols are used for data obtained while heating in air, closed symbols for heating in nitrogen. Error bars determined by propagation of uncertainties obtained in fitting data to Eq. (2).

proposed role of hydroperoxide radicals in the initial decomposition of PS under thermo-oxidative conditions. ${ }^{36}$

Initiation of polymer degradation is attributed to the existence of weak links, such as head-to-head ${ }^{43}$ hydroperoxy, and peroxy ${ }^{31}$ structures, within the polymer composites easily yielding at very low temperatures to form radicals that participate in subsequent degradation process at elevated temperatures. The increase in pyrolysis activation energies at lower conversion fractions $(\alpha<0.30)$ suggests a shift of the rate-limiting step from disintegration of these weak links to mainly random scission. Most researchers have attributed the improved thermal stability and fire retardancy in polymer/clay nanocomposites to the existence of a physical barrier limiting mass transport and energy transfer. However, thermal stabilization of polystyrene at conversion fractions of less than 0.30 , where no meaningful char formation would have occurred, suggests that chemical effect of clays may also contribute to the observed property enhancements. However, at higher degradation temperatures char formation may greatly contribute to the observed enhanced thermal stability via the "cage effect" phenomenon where the gaseous molecules formed during thermal decomposition are trapped within the solid inorganic-organic network. The complexity of decomposition reactions of polymeric materials precludes the authors from ascribing the stabilization effect at high degradation temperatures to char formation alone; several factors, including chemical reactions, might be at play as well.

The effectiveness of the additives on reducing the flammability of PS were measured using cone calorimetry; the parameters available include the heat release rate and especially its peak value, the peak heat release rate (PHRR); total heat release (THR); time to self sustained combustion (TSC); average mass loss rate (AMLR); and char yield (CY). Ideally, a decrease in the peak heat release 


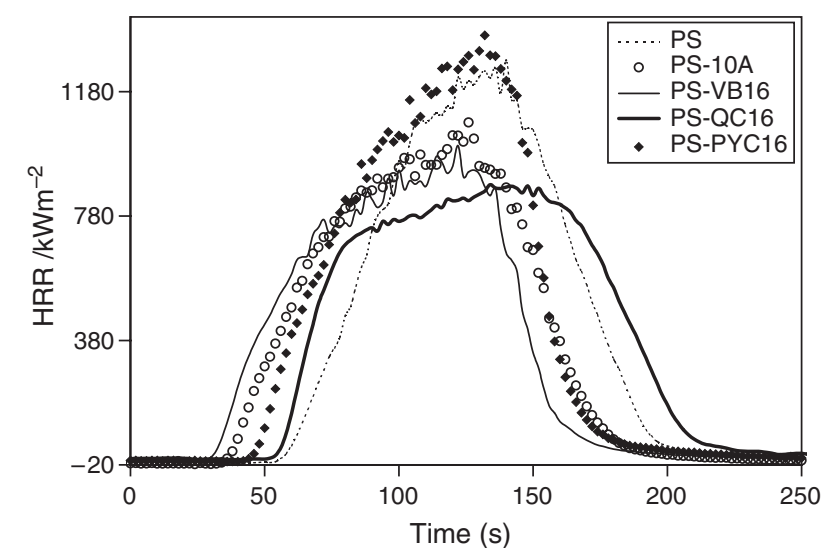

Fig. 9. Heat release rate curves pure PS (dashed line), PS-VB16 (solid line), PS-PYC16 (filled diamonds), PS-10A (empty circles), and PSQC16 (bold line) from cone calorimetry measurements at $35 \mathrm{~kW} / \mathrm{m}^{2}$. Curves for PS-PYC16 and PS-QC16 are as reported in Ref. [22].

rate, total heat released and the mass loss rate are desired along with an increase in char, time to sustained combustion and to reach the PHRR value. The heat release rate (HRR) as a function of time for pure PS and its composites at a flux of $35 \mathrm{~kW} / \mathrm{m}^{2}$ are shown in Figure 9. A somewhat significant reduction in the time to sustained combustion is observed for all the nanocomposites except for PS-QC16, where TSC remains the same compared to the virgin polymer. This correlates with the observed delay in the onset of thermal degradation seen in the TGA profile and the elevated pyrolysis activation energy for low conversions observed for PS-QC16 when compared to other nanocomposites. The HRR curves for the nanocomposites show that the evolution of heat is spread over a similar range of the combustion time as pure PS with the exception of PS-QC16 showing a prolonged combustion time. PS-PYC16 did not show any reduction in PHRR while PS-QC16 gave the greatest reduction, (34\%). A significant reduction in AMLR $(\sim 20 \%)$ was observed for PS-QC16, suggesting that a smaller amount of heat is released per unit time hence the reduction in PHRR. $T_{\mathrm{PHRR}}$ was prolonged for all the nanocomposites relative to pure PS, with PS-QC16 showing the greatest delay of $\sim 20 \%$. Addition of clay promotes char formation ${ }^{44}$ which heavily retards diffusion of combustible products from low temperature regime polymer pyrolysis hence the reduction in significant heat release rates for nanocomposites relative to the pure PS. Table II gives a summary of the results obtained for PS and its nanocomposites with different additives.

Zhu and coworkers ${ }^{1}$ prepared VB-16 containing polystyrene nanocomposites at various loadings via bulk polymerization. The TSC for the polystyrene nanocomposite was the same as for the pure PS unlike for the melt blending sample where a significant reduction is observed for the nanocomposite. More than two-fold improvements in PHRR, THR, AMLR, and ASEA were observed with bulk polymerized samples. ${ }^{1}$ This shows that the fire properties of polymer nanocomposites produced using different preparative methods are dissimilar. In making this proposition we assume the molecular weight distributions of the pure polystyrene and polystyrene nanocomposite are the same. However, the work reported does not mentioned molecular weight distributions for the obtained samples. Jang and coworkers ${ }^{30}$ reported a $55 \%$ reduction for a $5 \%$ loaded bulk polymerized polystyrene/10A nanocomposite. In this work we observed only a $16 \%$ reduction in PHRR for PS-10A. Gilman and coworkers ${ }^{25}$ suggested that significant reductions in the PHRR are a result of good nanodispersion of the additive within the polymer matrix. Even though TEM images show fairly good additive distribution in the polystyrene nanocomposites, cone calorimetry results suggest that the dispersion is not enough to cause remarkable reductions in the PHRR.

No significant percent reductions in the total heat released are observed for the nanocomposites under investigation. This suggests that even though a protective barrier is formed at the surface of the polymeric material its efficiency is not sufficient to effectively inhibit combustion. The formation of ceramic surfaces during combustion of polymeric material may serve to slow the flow of combustibles thus successfully reducing the flame intensity, however, without a significant reduction in the amount of polymeric material which has burned by the conclusion of the combustion process. The presence of the inorganic/ organic modifiers in the PS nanocomposites may provide heat sinks during combustion, perhaps via efficient thermal transfer of energy to metal components of the additives hence protecting polystyrene, which has a low thermal

Table II. Cone calorimetry data for polystyrene nanocomposites at a flux of $35 \mathrm{~kW} / \mathrm{m}^{2}$.

\begin{tabular}{|c|c|c|c|c|c|c|}
\hline Sample & $\begin{array}{l}\text { TSC } \\
(\mathrm{s})\end{array}$ & $\begin{array}{c}\text { PHRR } \\
\left(\mathrm{kW} / \mathrm{m}^{2}\right)(\% \mathrm{red})\end{array}$ & $\begin{array}{c}T_{\text {PHRR }} \\
(\mathrm{s})\end{array}$ & $\begin{array}{c}\text { THR } \\
\left(\mathrm{MJ} / \mathrm{m}^{2}\right)(\% \text { red })\end{array}$ & $\begin{array}{l}\text { AMLR } \\
\left(\mathrm{g} / \mathrm{stm}^{2}\right)\end{array}$ & $\begin{array}{l}\text { ASEA } \\
\left(\mathrm{m}^{2} / \mathrm{kg}\right)\end{array}$ \\
\hline PS & $59 \pm 4$ & $1284 \pm 180$ & $113 \pm 8$ & $99 \pm 9$ & $30 \pm 1$ & $1159 \pm 50$ \\
\hline PS/10A & $48 \pm 3$ & $1081 \pm 25$ & $120 \pm 7$ & $91 \pm 2(8)$ & $27 \pm 1(10)$ & $1187 \pm 14$ \\
\hline PS/QC16 ${ }^{a}$ & $60 \pm 2$ & $848 \pm 29(37)$ & $138 \pm 6$ & $94 \pm 3(6)$ & $24 \pm 1(22)$ & $1328 \pm 24$ \\
\hline PS/VB16 & $43 \pm 2$ & $1017 \pm 25$ & $129 \pm 12$ & $86 \pm 7(13)$ & $27 \pm 2(10)$ & $1150 \pm 23$ \\
\hline
\end{tabular}

TSC, time to sustained ignition; PHHR, peak heat release rate; $T_{\mathrm{PHHR}}$, time to peak heat release rate; THR, total heat release; AMLR, average mass loss rate; CY, char \%; ASEA, average specific extinction area (a measure of smoke). ${ }^{a}$ Previous work published elsewhere; Ref. [22]. 
conductivity. No significant reductions in the smoke content are observed for the polystyrene nanocomposites relative to the pure PS. The improvement in fire retardancy is shown by the reduction in the PHRR, reduction in AMLR in some cases, the increase in the $T_{\mathrm{PHRR}}$, and char remaining after complete combustion.

Kinetic information used to estimate the activation energies of polystyrene and its nanocomposites is derived solely from mass loss profiles of thermal degradation processes. The mathematical function used to describe the degradation process is modeled for the released products, i.e., from weight loss, and provides no information about which, or how many bonds are broken at any given conversion fraction. ${ }^{33}$ The extracted apparent $E_{\alpha}$ values are thus useful here to explain the shift to higher threshold temperatures for PS nanocomposites but not necessarily their flammability. It is imperative to recognize that kinetic analysis does not take into account mass transport and heat transfer during thermal decomposition of polymeric materials thus no correlation can be expected between activation energy trends and flammability property measurements from cone calorimetry.

For uninterrupted burning of polymeric material to occur, the initial heat must be adequate to cause decomposition of the material, the temperature high enough to ignite the products of thermal degradation, and the heat transferred back to the polymer sufficient to maintain the cycle. An effective fire retardant must be able to break this cycle somehow. This can be achieved by (i) enhancement in thermal stability of the polymeric material; (ii) quenching of the flame; and (iii) retardation of heat supply. MMT based flame-retardants may operate via several modes of action: (a) sacrificial absorption of heat by metallic $\mathrm{Mg}$ or $\mathrm{Al}$ (heat sink) from the intralayer structure of montmorillonite preventing heat transfer to polymeric material thus improving thermal stability; (b) dilution of combustion atmosphere by non-combustible gases $\left(\mathrm{H}_{2} \mathrm{O}\right.$ and $\left.\mathrm{CO}_{2}\right)$ generated from the thermal degradation of the additives (flame quenching); (c) the inorganic residual products may act as a physical barrier (cross-linked char) reducing diffusion of combustible matter (mass transport) and/or energy transfer, hence improving flame retardation. The success of a fire retardant depends on at least one, some or all of the modes of action described above.

\section{CONCLUSIONS}

The thermal stability, degradation kinetics, and combustion behaviors of PS and its nanocomposites have been studied using both TGA and cone calorimetry. In TGA experiments, significant increments in $T_{10}, T_{50}$, and $T_{\max }$ are observed for all additives under investigation. Addition of small amounts of the modified-MMT clays (5\%) to pure PS result in significant reductions in the peak heat release rate (PHRR) as measured using cone calorimetry with the exception of the PS-PYC16 nanocomposite. The average mass loss rate is reduced by $20 \%$ for PS-QC16 and this is consistent with the observed enhanced thermal stability measured from TGA experiments. However, there is no significant reduction in total heat release (THR).

Acknowledgments: We thank the Office of Naval Research (CAW, Grant N00014-03-1-0172) and NIST (JMH and CAW, Grant 60NANB6D6018) for financial assistance and M. Bartelt and J. Collins for technical support of the X-ray diffractometer.

\section{References and Notes}

1. J. Zhu, A. B. Morgan, F. J. Lamelas, and C. A. Wilkie, Chem. Mater. 13, 3774 (2001).

2. J. Zhu, F. M. Uhl, A. B. Morgan, and C. A. Wilkie, Chem. Mater. 13, 4649 (2001).

3. J. W. Gilman, W. H. Awad, R. D. Davis, J. Shields, R. H. Harris, C. Davis, A. B. Morgan, T. E. Sutto, J. Callahan, P. C. Trulove, and H. C. De Long, Chem. Mater. 14, 3776 (2002).

4. J. W. Gilman, C. L. Jackson, A. B. Morgan, R. Harris, E. Manias, E. P. Giannelis, M. Wuthenow, D. Hilton, and S. H. Phillips, Chem. Mater. 12, 1866 (2000).

5. Y. K. Kim, Y. S. Choi, K. H. Wang, and I. J. Chung, Chem. Mater. 14, 4990 (2002).

6. C.-R. Tseng, J.-Y. Wu, H.-Y. Lee, and F.-C. Chang, J. Appl. Poly. Sci. 85,1370 (2002).

7. T. A. Kim, S. T. Lim, C. H. Lee, H. J. Choi, and M. S. Jhon, J. Appl. Poly. Sci. 87, 2106 (2003).

8. J. M. Hwu, T. H. Ko, W.-T. Yang, J. C. Lin, G. J. Jiang, W. Xie, and W. P. Pan, J. Appl. Poly. Sci. 91, 101 (2004).

9. Z. Dong, Z. Li, J. Zhang, B. Han, D. Sun, Y. Wang, and Y. Huang, J. Appl. Poly. Sci. 94, 1194 (2004).

10. Z. Shen, F. Zhu, D. Liu, X. Zeng, and S. Lin, J. Appl. Poly. Sci. 95, 1412 (2005).

11. R. Qi, X. Jin, J. Nie, W. Yu, and C. Zhou, J. Appl. Poly. Sci. 97, 201 (2005).

12. Z. M. Wang, T. C. Chung, J. W. Gilman, and E. Manias, J. Poly. Sci. Part B: Poly. Phys. 41, 3173 (2003).

13. D. Schmidt, D. Shah, and E. P. Giannelis, Curr. Opin. Solid State Mater. Sci. 6, 205 (2005).

14. S. Bourbigot, J. W. Gilman, and C. A. Wilkie, Poly. Degrad. Stab. 84,483 (2005).

15. X. Fu and S. Qutubuddin, Mater. Lett. 42, 12 (2000).

16. A. Akelah and A. Moet, J. Mater. Sci. 31, 3589 (1996).

17. R. Krishnamoorti, R. A. Vaia, and E. P. Giannelis, Chem. Mater. 8, 1728 (1996)

18. R. A. Vaia, H. Ishii, and E. P. Giannelis, Chem. Mater. 5, 1694 (1993).

19. M. Sikka, L. N. Cerini, S. S. Ghosh, and K. I. Winey, J. Poly. Sci. Part B: Poly. Phys. 34, 1443 (1996).

20. L. A. Wall, S. Straus, J. H. Flynn, and D. McIntyre, J. Phys. Chem. 70,53 (1996).

21. F. Carasco and P. Pages, J. Appl. Poly. Sci. 61, 187 (1996).

22. G. Chigwada, D. Wang, and C. A. Wilkie, Poly. Degrad. Stab. 91, 848 (2006).

23. D. Wang, J. Zhu, Q. Yao, and C. A. Wilkie, Chem. Mater. 14, 3837 (2002).

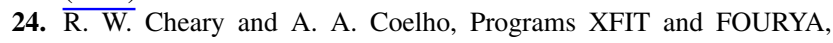
Deposited in CCP14, Powder Diffraction Library, Engineering and Physical Sciences Research Council, Daresbury Laboratory, Warrington, England (1996). 
25. J. W. Gilman, T. Kashiwagi, M. Nyden, J. E. T. Brown, C. L. Jackson, S. Lomakin, E. P. Giannelis, and E. Manias, Chemistry and Technology of Polymer Additives, edited by S. Al-Maliaka, A. Golovoy, and C. A. Wilkie, Blackwell Scientific, London (1999), pp. 249-265.

26. M. Kurata and Y. Tsunashima, Polymer Handbook, edited by J. Brandrup and E. H. Immerrgut, Wiley-Interscience, New York (1989), Section VII, p. 38.

27. B. Jang, Ph.D. Thesis, Marquette University (2005).

28. J. W. Gilman and A. B. Morgan, J. Appl. Poly. Sci. 87, 1329 (2003).

29. T. Lan, P. D. Kavirata, and T. J. Pinnavaia, Chem. Mater. 6, 573 (1994).

30. $\overline{\text { B. Jang }}$ and C. A. Wilkie, Polymer 46, 2933 (2005).

31. N. Grassie and G. Scott, Polymer Degradation and Stabilisation, Cambridge University Press (1985).

32. A. Khawam and D. Flanagan, J. Phys. Chem. B 109, 10073 (2005).

33. M. Maciejewski, J. Thermal. Anal. 33, 1269 (1988).

34. M. Maciejewski, Thermochim. Acta 355, 145 (2000).

35. J. D. Peterson, S. Vyazovkin, and C. A. Wight, J. Phys. Chem. B 103, 8087 (1999).
36. S. Vyazovkin, I. Dranca, X. Fan, and R. Advincula, J. Phys. Chem. B 108, 11672 (2004).

37. S. Vyazovkin and C. A. Wight, J. Phys. Chem. A 101, 8279 (1997).

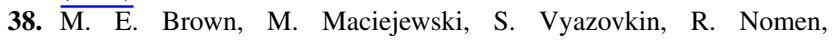
J. Sempere, A. Burnham, J. Opfermann, R. Strey, H. L. Anderson, A. Kemmler, R. J. Keuleers, J. Janssens, H. O. Desseyn, C.-R. Li, T. B. Tang, B. Roduit, J. Malek, and T. Mitsuhashi, Thermochim. Acta 355, 125 (2000).

39. T. Ozawa, Bull. Chem. Soc. Jpn. 38, 1881 (1965).

40. K. Pielichowski, K. Kulesza, and E. M. Pearce, J. Appl. Poly. Sci. 88,2319 (2003).

41. C. Wan, G. Tian, N. Cui, Y. Zhang, and Y. Zhang, J. Appl. Poly. Sci. 92, 1521 (2004).

42. E. Kandare, H. Deng, D. Wang, and J. M. Hossenlopp, Poly. Adv. Tech. 17, 312 (2006).

43. B. A. Howell, Y. Cui, and D. B. Priddy, Thermochim. Acta 396, 167 (2003).

44. J. Wang, J. Du, J. Zhu, and C. A. Wilkie, Poly. Degrad. Stab. 77, 249 (2002).

Received: 8 May 2007. Accepted: 6 July 2007. 